\title{
Potency of Vinegar Therapy in Otomycosis Patients
}

\author{
Eman Sulaiman, Bambang Purwanto, Lina Lasminingrum, \\ Yussy Afriani Dewi, Sally Mahdiani
}

\author{
Department of Ear Nose \& Throat and Head \& Neck Surgery \\ Faculty of Medicine Padjadjaran University/Hasan Sadikin General Hospital \\ Jl. Eykman No.38 Bandung \\ Email: emans_dr@yahoo.com
}

\begin{abstract}
Otomycosis is an outer ear canal infection caused by fungi. Clinicians are trying to find out the most effective antifungal drug for treating otomycosis. Traditionally, apple cider vinegar has been used for the treatment of various diseases, including antifungal.The high cost in otomycosis treatment effort, long duration of treatment, high recurrence rate, and the difficulty in the application of drugs in the otomycosis treatment have encouraged the researcher to do this study. The aim of this study is to measure clinical symptom's improvement, otoscopy observation and examination of $\mathrm{KOH} \mathrm{10 \%} \mathrm{in} \mathrm{patients} \mathrm{receiving} \mathrm{apple} \mathrm{cider} \mathrm{vinegar} \mathrm{therapy.}$ The method was descriptive study design from four otomycosis patients in the ORL HNS outpatient clinic of Hasan Sadikin Hospital Bandung from July to August 2014. The result showed there were clinical symptoms improvement, a better otoscopic observation and examination of $\mathrm{KOH} 10 \%$ in patients receiving apple cider vinegar. In other words, there were improvements of clinical symptoms, otoscopy view, and examination of $\mathrm{KOH} 10 \%$ in patients receiving apple cider vinegar therapy on seventh day. Conclusion of this study is by applicating apple cider vinegar gives improvement in clinical symptom, otoscopy view, and examination of $\mathrm{KOH} 10 \%$ in otomycosis patients.
\end{abstract}

Keywords: otomycosis, sign and symptoms improvement, apple cider vinegar. 


\title{
Potensi Larutan Cuka Apel pada Penderita Otomikosis
}

\author{
Eman Sulaiman,Bambang Purwanto, Lina Lasminingrum, \\ Yussy Afriani Dewi, Sally Mahdiani
}

\author{
Departemen Ilmu Kesehatan Telinga Hidung Tenggorok-Bedah Kepala Leher \\ Fakultas Kedokteran Universitas Padjadjaran/RS Dr. Hasan Sadikin \\ Jl.Eykman No.38 Bandung \\ Email: emans_dr@yahoo.com
}

\begin{abstract}
Abstrak
Otomikosis adalah infeksi kanalis akustikus eksterna yang disebabkan oleh jamur. Otomikosis menjadi tantangan bagi tenaga medis dan menyebabkan rasa frustasi bagi pasien. Klinisi masih terus berusaha menemukan obat otomikosis yang paling efektif. Secara tradisional cuka apel telah digunakan untuk pengobatan berbagai penyakit, diantaranya sebagai antijamur.

Mengingat biaya yang cukup tinggi, lamanya pengobatan, tingkat kekambuhan yang tinggi, serta sulitnya aplikasi obat dalam pengobatan otomikosis mendorong dilakukannya penelitian ini. Tujuan Penelitian ini adalah untuk menilai perbaikan gejala klinis, gambaran otoskopi, dan pemeriksaan $\mathrm{KOH} 10 \%$ pada penderita otomikosis yang mendapatkan terapi cuka apel. Metode yang digunakan adalah deskripsi dari dari empat penderita otomikosis di poliklinik THT-KL RS Hasan Sadikin pada Juli-Agustus 2014 dengan mengobservasi gejala klinis, gambaran otoskopi, dan pemeriksaan $\mathrm{KOH} 10 \%$. Hasil penelitian didapatkan perbaikan pada gejala klinis, gambaran otoskopi, dan hasil pemeriksaan $\mathrm{KOH} 10 \%$ pada keempat penderita otomikosis setelah terapi cuka apel setelah terapi hari ke-7.

Simpulan: Pemberian cuka apel topikal pada pasien otomikosis memberikan hasil yang baik dalam perbaikan gejala klinis, gambaran otoskopi, dan hasil pemeriksaan $\mathrm{KOH} 10 \%$.
\end{abstract}

Kata kunci : otomikosis, perbaikan tanda dan gejala, cuka apel 


\section{Research Article}

\section{Pendahuluan}

Otomikosis adalah infeksi pada kanalis akustikus eksterna yang disebabkan oleh jamur. ${ }^{1}$ Otomokosis merupakan salah satu kondisi yang sering dihadapi oleh dokter umum ataupun dokter ahli Telinga Hidung dan Tenggorok (THT). Otomikosis jarang mengancam kehidupan, tetapi menjadi tantangan bagi tenaga medis dan menyebabkan rasa frustasi bagi pasien oleh karena memerlukan pengobatan dan tindak lanjut jangka panjang, serta tingkat kekambuhan yang cukup tinggi. ${ }^{2}$

Otomikosis dan infeksi lain yang disebabkan oleh jamur lebih sering terjadi pada daerah yang beriklim tropis dan subtropis seperti halnya negara Indonesia. ${ }^{2}$ Insidensi otomikosis yang semakin meningkat berhubungan dengan berbagai macam faktor predisposisi diantaranya penggunaan antibiotik tetes telinga yang luas dan tidak perlu, penggunaan antibiotik sistemik spektrum luas, iklim lembab, pembersihan serumen yang berlebihan, trauma lokal, instrumentasi telinga, dan pasien dengan kondisi immuno compromized. ${ }^{3}$

Data prevalensi otomikosis yang didapatkan dari beberapa hasil penelitian adalah sebesar 6\% di antara semua pasien yang mengeluhkan kelainan gejala di telinga, dan mencapai angka 25\% diantara kasus otitis eksterna yang diakibatkan oleh agen infeksi. ${ }^{4}$ Angka kunjungan penderita otomikosis di poliklinik Otologi THT-KL Rumah Sakit Hasan Sadikin Bandung selama periode bulan Januari 2012 sampai dengan bulan Desember 2012 tercatat 7,45\% dari seluruh total pasien dengan perbandingan $75,8 \%$ pasien wanita dan $24,2 \%$ pasien $_{\text {pria. }}{ }^{5}$

Gejala klinis yang paling sering ditemukan pada pasien otomikosis adalah rasa nyeri/ terbakar di telinga, gatal, sensasi penuh pada telinga, keluar sekret dari telinga, penurunan pendengaran, tinitus, dan nyeri kepala hebat. ${ }^{6}$ Pada pemeriksaan dengan menggunakan otoskopi tampak menunjukkan adanya edema, hiperemis kulit kanalis akustikus eksterna, sekret telinga, dan adanya koloni jamur/miselium Pada tahap awal infeksi, pertumbuhan jamur terlihat sebagai spora berwarna putih atau hitam pada infeksi yang disebabkan Aspergillus spp atau adanya deposit "creamy" atau kental pada infeksi yang disebabkan oleh Candida spp. Pada tahap selanjutnya akan tampak kotoran berwarna putih kotor seperti serpihan kertas yang basah, lengket, berbintik-bintik yang memenuhi kanalis akustikus eksterna dan peradangan yang semakin luas pada kanalis akustikus eksterna. ${ }^{3}$

Berbagai spesies jamur telah diidentifikasi sebagai penyebab otomikosis. Aspergillus spp dan Candida spp adalah jamur patogen tersering yang menyebabkan otomikosis. Aspergillus spp adalah organisme penyebab dominan otomikosis di daerah tropis dan subtropis. ${ }^{6}$

Dalam melakukan diagnosis otomikosis, selain gejala klinis dan temuan dari gambaran otoskopi,diperlukan pemeriksaan penunjang berupa pemeriksaan dengan larutan $\mathrm{KOH} 10 \%$ untuk melihat elemen jamur dan kultur jamur yang positif., 7

Pada saat ini penemuan obat antijamur yang baru telah mengalami perkembangan yang pesat baik yang berbentuk topikal maupun sistemik dan diharapkan prevalensi penyakit infeksi jamur dapat 


\section{Research Article}

berkurang. Pengetahuan tentang mekanisme kerja, aktivitas, spektrum, farmakokinetik, efek samping maupun interaksi obat antijamur sangat diperlukan dalam memberikan pengobatan. ${ }^{9}$

Banyak sediaan antijamur yang telah direkomendasikan untuk mengobati otomikosis tapi belum ada yang diterima secara luas dan belum cukup memastikan penyembuhan secara lengkap. Sampai saat ini para klinisi masih terus berusaha untuk menemukan obat yang paling efektif untuk mengobati otomikosis ini. Berbagai obat antimikosis ini mencapai popularitas hanya dalam waktu yang singkat, sampai efek samping yang tidak diinginkan teridentifikasi atau obat jenis baru muncul di pasaran. ${ }^{10}$ Sampai saat ini belum terdapat sediaan antijamur tetes telinga yang telah disetujui dan disahkan oleh lembaga Food Drug Assosiation (FDA) untuk pengobatan otomikosis. ${ }^{3}$

Beberapa permasalahan yang dihadapi pada pemberian terapi otomikosis yaitu: terjadinya resistensi, sedikitnya data mengenai keamanan penggunaan obat ototopikal, efek iritasi antijamur topikal terhadap mukosa telinga tengah, toksisitas sistemik antijamur (hepatotoksisitas dan nefrotoksisitas), masalah ini mendorong para peneliti untuk menemukan terapi otomikosis yang lebih aman dan efektif. ${ }^{3}$ Sampai saat ini, terdapat empat kelas utama obat untuk pengobatan infeksi jamur, yaitu: golongan poliena, triazoles, analog nukleosida, dan echinocandins. ${ }^{6}$

Mengingat biaya yang cukup tinggi dalam upaya pengobatan otomokosis, lamanya waktu pengobatan, dan juga tingkat kekambuhan yang tinggi, serta sulitnya aplikasi obat dalam pengobatan otomikosis, maka kami menggunakan larutan cuka apel yang ekonomis dan mudah didapatkan. ${ }^{3}$

Cuka apel adalah cuka yang diproses secara organik dari buah apel. Cuka apel adalah produk dari fermentasi dimana gula dalam apel dipecah oleh bakteri dan ragi. Dalam tahap pertama fermentasi, gula berubah menjadi alkohol. Kemudian, alkohol meragi lanjut menjadi cuka apel. ${ }^{11}$ Bakteri yang digunakan pada proses pembuatan cuka apel yang disebut juga bakteri asam asetat termasuk genus Acetobacter yang ditandai oleh kemampuan nya merubah etil alkohol $\left(\mathrm{C}_{2} \mathrm{H}_{5} \mathrm{OH}\right)$ menjadi asam asetat $\left(\mathrm{CH}_{3} \mathrm{CO}_{2} \mathrm{H}\right)$ melalui proses oksidasi. ${ }^{12}$

Para ilmuwan telah meneliti 90 kandungan zat yang terdapat pada cuka apel, zat-zat tersebut diantaranya: 13 jenis asam karbol, empat jenis aldehida, 20 jenis keton, 18 jenis alkohol, delapan jenis etil asetat, mineral penting, vitamin, asam asetat, asam propionat, asam laktat dan asam malat, enzim, asam amino, serta serat dalam bentuk kalium dan pektin, mineral (Kalium, Kalsium, Magnesium, Fosfor, Chlorine, Sodium, Sulfur, Tembaga, Besi, Silikon, Fluorin), vitamin (Vitamin C, Vitamin E, Vitamin A, Vitamin $B_{1}$, Vitamin $B_{2}$, Vitamin $B_{6}$, Provitamin beta-karoten 11). ${ }^{13}$

Secara tradisional cuka apel telah secara luas digunakan untuk pengobatan berbagai macam penyakit diantaranya: menurunkan kadar kolesterol darah, meregulasi tekanan darah, menurunkan berat badan, anti bakteri, dan antijamur, sebagai terapi antijamur secara tradisional, yaitu untuk terapi penyakit jamur yang mengenai kulit, kuku, vagina. ${ }^{3}$ 


\section{Research Article}

Pada penelitian yang dilakukan oleh Jabir H B, dkk (2012) tentang perbandingan potensi antijamur larutan cuka apel, larutan asam asetat 2\%, dan Flukonazol secara invitro, didapatkan bahwa larutan cuka apel $(5 \%)$ menunjukkan efek antijamur yang signifikan $(\mathrm{p}<0,05)$ terhadap Aspergillus niger, Aspergillus flavus, Candida albicans, dan Non Candida. Hasil tersebut sejalan dengan hasil penelitian lain yang menyimpulkan bahwa aplikasi topikal cuka apel efektif untuk pengobatan folikulitis yang disebabkan oleh Pityrosporum ovale. ${ }^{13}$

Aktivitas antijamur dari cuka apel dikaitkan dengan kandungan asam malat, asam asetat, serta zat aktif lain yang belum teridentifikasi. ${ }^{3}$ Asam asetat mempunyai dua efek terhadap sel jamur, yang pertama adalah menyebabkan pemisahan sel jamur dengan dinding kanalis akustikus eksterna tempat dimana sel jamur menempel, yang kedua adalah mengganggu keseimbangan asam basa sehingga menyebabkan kematian sel jamur, dan menghambat proliferasi sel jamur. Sedangkan obat antijamur lain seperti Klotrimazol hanya berefek menghambat proliferasi sel jamur. ${ }^{14}$

Penelitian ini bertujuan menilai efek terapi cuka apel terhadap gejala klinis, gambaran otoskopi dan hasil pemeriksaan $\mathrm{KOH} 10 \%$ pada penderita otomokosis.

\section{Metode}

Penelitian dilakukan di poliklinik THT-KL RSHS dari tanggal 20 Juni sampai dengan 20 Juli 2013, berupa kasus serial dari empat orang penderita otomokosis. Kriteria inklusi pada penelitian ini adalah pasien dengan diagnosis otomikosis didasarkan pada anamnesis, pemeriksaan otoskopi, dan hasil positif pada pemeriksaan mikrobiologi dengan $\mathrm{KOH} \mathrm{10 \% ,} \mathrm{membran} \mathrm{timpani} \mathrm{intak,otomikosis}$ unilateral. Kriteria eksklusi pada penelitian ini adalah penderita otomikosis yang sedang atau telah mendapat terapi sebelumnya, penderita Diabetes Melitus, memiliki gangguan imunitas tubuh, pernah mendapat tindakan operasi pada telinga, menderita otitis eksterna dengan stenosis pada kanalis akustikus eksterna (KAE).

Dilakukan perhitungan skor gejala otomikosis dengan mengisi kuesioner Visual analog Score (VAS). Pasien diminta menilai beratnya keluhan (rasa terbakar di telinga, gatal-gatal, sensasi penuh pada telinga, nyeri telinga, keluar cairan dari telinga, penurunan pendengaran, dan tinnitus.

Belum ada klasifikasi terstandarisasi untuk menilai derajat berat ringannya gambaran otoskopi otomikosis, sehingga peneliti membuat klasifikasi gambaran otoendoskopi otomikosis. Diharapkan klasifikasi yang penulis buat dapat digunakan dan diaplikasikan dalam penatalaksanaan pasien otomikosis pada praktek sehari-hari:

1). Adanya sekret pada kanalis akustikus eksterna, dengan klasifikasi:

$(+++)$ : Jumlah sekret banyak, memenuhi seluruh kanalis akustikus eksterna

$(++)$ : Jumlah sekret cukup banyak, memenuhi sebagian kanalis akustikus eksterna 


\section{Research Article}

(+) : Jumlah sekret sedikit

(-) : Tidak terdapat sekret

2). Edema pada dinding kanalis akustikus eksterna,dengan klasifikasi:

$(+++)$ : Edema pada seluruh dinding kanalis akustikus eksterna

$(++) \quad$ : Edema pada sebagian dinding kanalis akustikus eksterna

$(+) \quad$ : Edema pada sebagian kecil dinding kanalis akustikus eksterna

(-) : : Tidak terdapat edema pada kanalis akustikus eksterna

3). Hiperemis pada dinding kanalis akustikus eksterna,dengan klasifikasi:

$(+++)$ : Hiperemis pada seluruh dinding kanalis akustikus eksterna

$(++) \quad$ : Hiperemis pada sebagian dinding kanalis akustikus eksterna

(+) : Hiperemis pada sebagian kecil dinding kanalis akustikus eksterna

(-) : : Tidak terdapat hiperemis pada kanalis akustikus eksterna

4).Koloni jamur/miselium, dengan klasifikasi:

$(+++)$ : Jumlah koloni jamur/miselium banyak, memenuhi seluruh kanalis akustikus eksterna

$(++)$ : Jumlah koloni jamur/miselium cukup banyak, memenuhi sebagian kanalis akustikus eksterna

(+) : Jumlah koloni jamur/miselium sedikit

(-) : Tidak terdapat koloni jamur/miselium

Dilakukan pengambilan sampel sekret dari kanalis akustikus eksterna untuk dilakukan pemeriksaan preparat langsung dengan $\mathrm{KOH} \mathrm{10 \% .} \mathrm{Selanjutnya} \mathrm{dilakukan} \mathrm{spooling} \mathrm{dengan} \mathrm{larutan}$ $\mathrm{H}_{2} \mathrm{O}_{2} 3 \%$ dan pembersihan sel jamur pada kanalis akustikus eksterna.

Pemberian terapi cuka apel dilakukan dengan cara diteteskan pada telinga yang 3x sehari masing-masing 5 tetes. Setelah itu dipasangkan tampon pada telinga pasien. Pada hari ke-7 pasien kontrol kembali ke poli THT-KL RSHS untuk dievaluasi pembandingan gejala klinis otomikosis sebelum dan sesudah dilakukan terapi dengan menggunakan alat ukur berupa Visual Analogue Scale $(V A S)$ dan perubahan gambaran pemeriksaan otoskopi, dan pemeriksaan langsung dari apus kanalis akustikus eksterna dengan $\mathrm{KOH} 10 \%$. 


\section{Skema Alur Kerja}

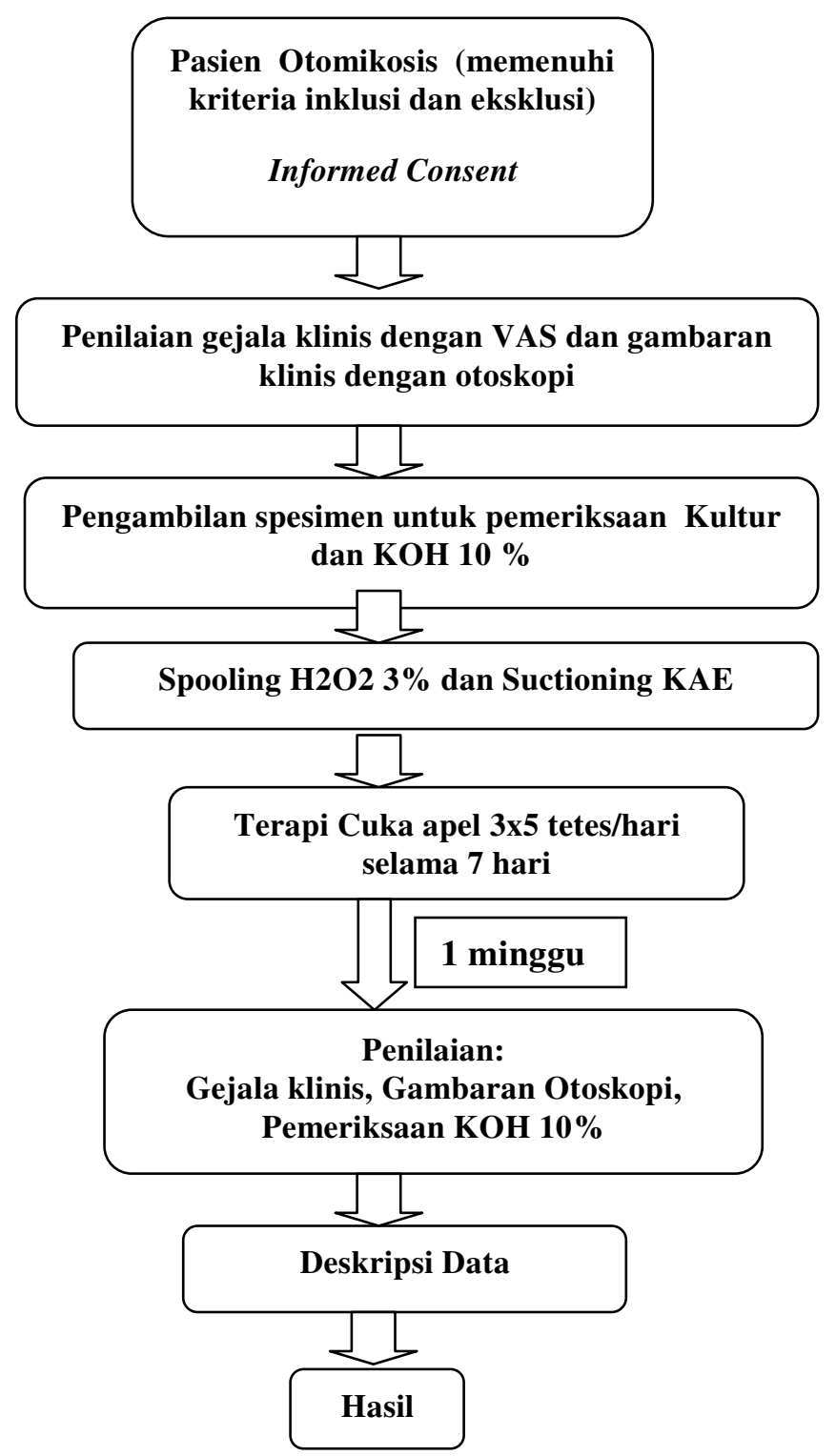




\section{Research Article}

Hasil

Selama periode Juli sampai dengan Agustus 2014 dilakukan penelitian di Poli THT-KL RS Hasan Sadikin Bandung terhadap empat pasien otomikosis.

Tabel 1 Karakteristik pasien yang mendapatkan terapi larutan cuka apel

\begin{tabular}{lcccc}
\hline \multicolumn{1}{c}{ Pasien } & $\mathbf{1}$ & $\mathbf{2}$ & $\mathbf{3}$ & $\mathbf{4}$ \\
\hline Jenis kelamin & Perempuan & laki-laki & laki-laki & laki-laki \\
Usia & 21 tahun & 71 tahun & 55 tahun & 67 tahun \\
Suku & Sunda & sunda & jawa & sunda \\
Agama & Islam & islam & islam & islam \\
Pendidikan & S1 & D3 & SMP & SD \\
Pekerjaan & Mahasiswi & pensiunan PNS & pedagang & buruh \\
Telinga Yang Terinfeksi & Kiri & Kanan & Kiri & Kanan \\
\hline
\end{tabular}

Tabel 2 Gejala klinis pasien sebelum dan setelah mendapatkan terapi larutan cuka apel

\begin{tabular}{lccccccccc}
\hline \multirow{2}{*}{\multicolumn{1}{c}{ Gejala Klinis }} & \multicolumn{7}{c}{ Angka Berat Keluhan berdasarkan VAS } \\
\cline { 2 - 8 } & \multicolumn{2}{c}{ Pasen 1 } & \multicolumn{2}{c}{ Pasen2 } & \multicolumn{2}{c}{ Pasen 3 } & Pasen 4 \\
\cline { 2 - 8 } & Hari 0 & Hari ke-7 & 0 & Hari ke-7 & Hari 0 & 7 & Hari 0 & Hari ke-7 \\
\hline Nyeri telinga & 4 & 2 & 0 & 0 & 0 & 0 & 0 & 0 \\
Telinga terasa penuh & 5 & 1 & 8 & 3 & 3 & 1 & 7 & 2 \\
Gatal & 0 & 0 & 9 & 0 & 5 & 0 & 3 & 0 \\
Keluar cairan dari telinga & 6 & 2 & 0 & 0 & 0 & 0 & 0 & 0 \\
Penurunan pendengaran & 4 & 2 & 8 & 2 & 6 & 0 & 6 & 2 \\
Telinga berdenging/bergemuruh & 0 & 0 & 0 & 0 & 0 & 0 & 0 & 0 \\
\hline
\end{tabular}

Tabel 3 Gambaran Otoskopi pasien sebelum dan setelah mendapatkan terapi larutan cuka apel

\begin{tabular}{lccccccccc}
\hline \multirow{2}{*}{ Gambaran Otoskopi } & \multicolumn{2}{c}{ Pasien 1 } & \multicolumn{2}{c}{ Pasien 2 } & \multicolumn{2}{c}{ Pasien 3 } & \multicolumn{2}{c}{ Pasien 4 } \\
\cline { 2 - 9 } & Hari 0 & Hari ke-7 & Hari 0 & Hari ke-7 & Hari 0 & Hari ke-7 & Hari 0 & Hari ke-7 \\
\hline Sekret pada CAE & +++ & + & - & - & - & - & - & - \\
Edema pada CAE & ++ & + & ++ & + & ++ & - & + & - \\
Hiperemis pada CAE & +++ & + & +++ & + & ++ & + & ++ & + \\
Koloni jamur/miselium & + & - & +++ & - & ++ & - & +++ & ++ \\
\hline
\end{tabular}


Tabel 4 Hasil Pemeriksaan KOH 10\% dan Kultur Jamur

\begin{tabular}{|c|c|c|c|}
\hline & \multicolumn{2}{|c|}{ Hasil Pemeriksaan KOH 10\% } & \multirow{2}{*}{ Kultur Jamur } \\
\hline & Hari 0 & Hari ke-7 & \\
\hline Pasien 1 & + & - & Aspergillus niger \\
\hline Pasien 2 & + & - & - \\
\hline Pasien 3 & + & - & Candida glabrata \\
\hline Pasien 4 & + & - & Aspergillus sp. \\
\hline
\end{tabular}

\section{Diskusi}

Dari keempat penderita tersebut, 1 orang adalah perempuan dan 3 orang laki-laki. Berdasarkan data angka kunjungan penderita otomikosis di Poliklinik rawat jalan THT-KL Rumah Sakit DR. Hasan Sadikin Bandung periode Januari sampai Desember 2012 dimana jumlah pasien wanita $(75,8 \%)$ lebih banyak dibandingkan dengan dan pasien pria $(24,2 \%){ }^{5}$ Angka kejadian otomikosis lebih banyak pada perempuan juga didapatkan pada penelitian yang dilakukan oleh Moghadam AY, dkk, dan Kiakojuri K, dkk. ${ }^{10,15}$

Hasil yang berbeda dilaporkan oleh Ho T, dkk, Satish HS, dkk, Gutierrez PH ,dkk, Pradhan, dkk, serta Mgbor N, dkk, bahwa otomikosis lebih sering dialami oleh laki-laki dibandingkan dengan perempuan. $2,3,4,16,17$

Angka kejadian otomikosis yang lebih banyak dialami oleh laki-laki dikaitkan dengan faktor predisposisi berupa paparan terhadap lingkungan kerja, kegiatan olahraga, dan kegiatan di luar rumah yang lebih sering dilakukan laki-laki. ${ }^{4}$

Data yang berbeda berkaitan dengan angka kejadian otomikosis berdasarkan jenis kelamin masih belum dapat dijelaskan secara pasti. Hal ini disebabkan oleh faktor predisposisi otomikosis yang bervariasi. Angka kejadian otomikosis yang lebih banyak dialami oleh perempuan salah satunya dikaitkan dengan faktor predisposisi yang berhubungan dengan penggunaan penutup kepala (hijab), hal ini berkaitan dengan sifat dari jamur yang tumbuh lebih subur pada kelembaban yang tinggi mencapai $80 \%$, dan temperatur yang lebih tinggi berkisar $37^{\circ} \mathrm{C}$ merupakan lingkungan ideal untuk pertumbuhan jamur. ${ }^{16,18,19}$

Usia penderita pada data yaitu berusia $21,55,67$, dan 71 tahun. Data usia pasien otomikosis pada penelitian ini sejalan dengan beberapa penelitian lain yang telah disebutkan diatas, bahwa kejadian otomikosis tersering terjadi pada rentang usia aktif. Hal ini diakibatkan oleh tingginya paparan terhadap spora dan miselium jamur pada lingkungan kerja, sekolah/tempat pendidikan, perjalanan, dan tempat aktivitas lain pada usia aktif, sedangkan pada usia yang lebih muda dan lebih tua mempunyai kemungkinan yang lebih kecil terpapar patogen penyebab otomikosis. ${ }^{16}$ 


\section{Research Article}

Etiologi otomikosis tersering adalah jamur saprofit yang banyak terdapat di alam dan lingkungan sekitar dan menjadi bagian dari flora komensal pada kanalis akustikus eksterna sehingga semakin tinggi aktivitas seseorang di lingkungan luar rumah semakin tinggi kemungkinan untuk terpapar spora dan miselium jamur. ${ }^{2}$

Dua orang pasien mengalami otomikosis di telinga kanan dan dua orang lainnya pada telinga kirinya. Dibandingkan dengan data hasil penelitian yang dilakukan oleh Moghadam AY, dkk (2010) mengenai efek campuran alkohol dan asam asetat pada 52 orang pasien otomikosis didapatkan bahwa telinga yang terinfeksi terdiri dari telinga kanan sebesar 40,4\%, telinga kiri 34,6\%, dan yang mengenai kedua telinga sebesar $25 \%{ }^{18}$

Hal serupa juga didapatkan pada penelitian yang dilakukan oleh Pradhan, dkk (2000) yang melakukan penelitian terhadap 100 pasien otomikosis di Nepal, didapatkan bahwa telinga yang terinfeksi terdiri dari telinga kanan sebesar $47,5 \%$, sebelah kiri 44,4\%, dan yang mengenai kedua telinga sebesar $8,1 \%{ }^{3}$

Dari hasil pemeriksaan didapatkan bahwa terdapat perbaikan gejala klinis pada keempat pasien otomikosis yang mendapatkan terapi tetes larutan cuka apel pada hari ke-7, baik berupa keluhan otalgia, telinga terasa penuh, gatal, otore, penurunan pendengaran, dan tinnitus. Begitu pula dengan gambaran otoskopi, terdapat perbaikan pada keempat pasien baik berupa sekret, edema, hiperemis, dan koloni/ miselium jamur pada kanalis akustikus eksterna. Dengan kata lain pemberian tetes telinga cuka apel pada pasien otomikosis berpengaruh pada perbaikan gejala klinis dan perbaikan gambaran otoskopi.

Pada keempat sediaan yang dilakukan pemeriksaan $\mathrm{KOH} 10 \%$ didapatkan hasil positif memberikan gambaran hifa, pseudo hifa, dan spora yang menunjukkan bahwa infeksi diakibatkan oleh jamur, dan setelah pemberian tetes cuka apel selama 7 hari, pemeriksaan $\mathrm{KOH} 10 \%$ seluruhnya menjadi negatif. Hal ini menunjukkan pemberian cuka apel berpengaruh pada eradikasi jamur pada keempat penderita otomikosis.

Pada pemeriksaan kultur jamur didapatkan hasil yang positif terdapat pertumbuhan jamur pada ketiga sediaan, dan setelah dilakukan identifikasi di dapatkan spesies jamur yaitu: Aspergillus niger, Candida glabrata, Aspergillus sp. sedangkan pada satu sediaan tidak didapatkan pertumbuhan jamur. Hal ini sesuai dengan berbagai literatur yang mengidentifikasi berbagai macam spesies jamur sebagai penyebab otomikosis. Aspergillus $s p$ dan Candida $s p$ merupakan agen tersering penyebab otomikosis. Aspergillus merupakan penyebab tersering otomikosis pada daerah dengan iklim tropis dan subtropis. Spesies jamur lain yang menyebabkan otomikosis yaitu: Pityrosporum, Penicillium, Dermatophyta (Trichophyton, Epidermophyton, Mikrosporum). 2, 3, 4, 13 


\section{Research Article}

\section{Simpulan}

1. Pemberian tetes telinga cuka apel pada pasien otomikosis memberikan hasil yang baik dalam perbaikan gejala klinis keempat pasien, berupa perbaikan keluhan otalgia, telinga terasa penuh, gatal, otore, penurunan pendengaran, dan tinitus.

2. Pemberian tetes telinga cuka apel pada pasien otomikosis memberikan hasil yang baik pada gambaran otoskopi keempat pasien berupa sekret, edema, hiperemis, dan koloni/ miselium jamur pada kanalis akustikus eksterna.

3. Perbaikan hasil pemeriksaan mikroskopis dengan $\mathrm{KOH} 10 \%$ pada keempat pasien setelah terapi tetes cuka apel.

\section{Saran}

Perlu dilakukan uji klinis dengan menggunakan jumlah sampel yang lebih besar untuk membuktikan potensi pemberian topikal cuka apel dalam perbaikan gejala klinis, gambaran otoskopi, dan pemeriksaan $\mathrm{KOH} 10 \%$ pada penderita otomikosis, serta penentuan konsentrasi cuka apel yang tepat sehingga didapatkan dosis optimal dengan efek samping seminimal mungkin.

\section{Daftar Pustaka}

1. Probst R,Grevers G, Iro H. The Middle Ear, Dalam: Basic Otorhinolaryngology A Step by Step Learning Guide. Georg Thieme Verlag Stuttgart Newyork. 2006.p 227-31

2. Ho T, Vrabec JT, Yoo D, Coker NJ. Otomycosis: Clinical Features and Treatment Implications. Otolaryngol-Head Neck Surgery. 2006;135: 787-91

3. Pradhan B, Tuladhar NR, Amatya RM. Prevalence of Otomycosis In Outpatient Department of Otolaryngology in Tribhuvan University Teaching Hospital, Kathmandu, Nepal. Ann Otol Rhinol Laryngol. 2003;112: 384-7

4. Gutierrez PH, Alvarez SJ, Sanudo EGC, García LMGC, Sanchez CR, Valdezate LAV. Presumed diagnosis: Otomycosis: A study of 451 patients. Acta Otorrinolaringol Esp. 2005; 56:181-6

5. Buku daftar kunjungan poliklinik Otologi di Bagian THT-KL FKUP Perjan RS Dr. Hasan Sadikin Bandung. 2012

6. Alnawaiseh S. Treatment of Otomycosis: A Comparative Study Using Miconazole Cream with Clotrimazole Otic Drops. Journal of the Royal Medical Services. 2011;18(3): 34-7

7. Linstrom CJ, Lucente FE. Dieses of the External Ear. Dalam: Bailey, Byron J; Johnson, Jonas T; Newlands, Shawn D. Head \& Neck Surgery-Otolaryngology. Lippincott Williams \& Wilkins. New York. 2006;5: 2333-57

8. Lalwani AK. External \& middle ear: Diseases of the external ear. Dalam: Lalwani AK ed. Current diagnosis \& treatment, Head \& Neck Surgery. Mc Graw Hill's-Lange. New York. 2004.p 30-3

9. Paramata NR, Maidin A, Massi N. Perbandingan Uji Kepekaan Itrakonazol Terhadap Agen Penyebab Dermatofitosis Pada Kulit Glabrous Di Makassar. Bagian Mikrobiologi, Fakultas Kedoketran Unhas Makassar. 2008: 1-12

10.Kiakojuri K, Roushan MRH, Sepidgar SAA. Suction Clearance And 2\% Topical Miconazole Versus The Same Combination With Acidic Drops In The Treatment Of Otomycosis. Department of Otolaryngology Shahid Beheshti Teaching Hospital, Babol Medical University. Iran. 2007; 38: 749-53

11.Winarsih S, Hidayati N, Subramaniam T. The Antibacterial Effect of Apple Cider Vinegar on The Growth Of Escherichia Coli (Faeces Isolates) In Vitro. Laboratorium Mikrobiologi Universitas Brawijaya. 2009:1-15

12.Tan SC. Vinegar Fermentation. Department of Food Science. Mechanical Engineering, University of Louisiana at Lafayette. 2003.p 45-67

13.Jabir H B Abbas FRN, Khalaf R N. In Vitro Assessment of Antifungal Potential of Apple Cider Vinegar and Acetic Acid Versus Fluconazole In Clinical Isolates Of Otomycosis. Thi-Qar Medical Journal (TQMJ). 2011;5(1):126-33

14.Malik AA, Malik SN, Aslam MA.. Comparative efficacy of topical clotrimazole and 3\% salicylic acid in otomycosis. Rawal Med J Pakistan. 2012:1-12

15.Kiakojuri K, Roushan MRH, Sepidgar SAA. Suction Clearance and 2\% Topical Miconazole Versus the Same Combination with Acidic Drops in The Treatment of Otomycosis. Department of Otolaryngology Shahid Beheshti Teaching Hospital, Babol Medical University. Iran. 2007; 38: 749-53

16.Satish HS, Vishwanatha, Manjuladevi. A Clinical Study of Otomycosis. IOSR J Dent Med Sci. 2013; 5(2): 57-62 


\section{Research Article}

17.Mgbor N, Gugnani HC.. Otomycosis in Nigeria: Treatment with Mercurochrom. Departement of Otolaryngology University of Nigeria Teaching Hospital. Mycoses Journal. 2001; 44: 395-7

18.Yaganeh MA.. Evaluating the Effect of a Mixture of Alcohol and Acetic Acid for Otomycosis Therapy. Jundishapur J Microbiol, Iran. 2010; 3(2): 66-70

19.Ozcan K, Ozcan M, Karaarslan A, Karaarslan F. Otomycosis In Turkey, Predisposising Factors, Etiology and Therapy. J Laryngology \& Otolaryngol. 2003;117: 39-42 